\title{
Novel Insights into the Vasoprotective Role of Heme Oxygenase-1
}

\author{
Emanuela Marcantoni, ${ }^{1,2}$ Luigia Di Francesco, ${ }^{2,3}$ Melania Dovizio,,${ }^{1,2}$ Annalisa Bruno, ${ }^{1,2}$ \\ and Paola Patrignani ${ }^{2,3}$
}

${ }^{1}$ Department of Medicine and Aging, School of Medicine, “G. d'Annunzio" University, 66100 Chieti, Italy

${ }^{2}$ Center of Excellence on Aging (CeSI), School of Medicine, "G. d'Annunzio" University, 66100 Chieti, Italy

${ }^{3}$ Department of Neuroscience and Imaging, School of Medicine, "G. d'Annunzio" University, 66100 Chieti, Italy

Correspondence should be addressed to Paola Patrignani, ppatrignani@unich.it

Received 31 October 2011; Accepted 12 December 2011

Academic Editor: David Sacerdoti

Copyright (C) 2012 Emanuela Marcantoni et al. This is an open access article distributed under the Creative Commons Attribution License, which permits unrestricted use, distribution, and reproduction in any medium, provided the original work is properly cited.

Cardiovascular risk factors contribute to enhanced oxidative stress which leads to endothelial dysfunction. These events trigger platelet activation and their interaction with leukocytes and endothelial cells, thus contributing to the induction of chronic inflammatory processes at the vascular wall and to the development of atherosclerotic lesions and atherothrombosis. In this scenario, endogenous antioxidant pathways are induced to restrain the development of vascular disease. In the present paper, we will discuss the role of heme oxygenase (HO)-1 which is an enzyme of the heme catabolism and cleaves heme to form biliverdin and carbon monoxide (CO). Biliverdin is reduced enzymatically to the potent antioxidant bilirubin. Recent evidence supports the involvement of HO-1 in the antioxidant and antiinflammatory effect of cyclooxygenase(COX)-2-dependent prostacyclin in the vasculature. Moreover, the role of HO-1 in estrogen vasoprotection is emerging. Finally, possible strategies to develop novel therapeutics against cardiovascular disease by targeting the induction of $\mathrm{HO}-1$ will be discussed.

\section{Introduction}

For many years, atherosclerosis was considered an agerelated process characterized by the passive accumulation of lipids in the vessel wall. However, the most recent lines of evidence have clearly shown that it is a complex process in which multiple pathogenic factors contribute to trigger and sustain vessel wall damage, leading to myocardial infarction, stroke, and sudden death [1]. In particular, there is an increasing appreciation of atherosclerosis as a dynamic and progressive disease starting with endothelial dysfunction which may trigger platelet activation and their interaction with leukocytes and endothelial cells. This process may contribute to the induction of chronic inflammation at the vascular wall [2].

Several lines of evidence suggest that oxidative stress may promote endothelial dysfunction through increased production of reactive oxygen species (ROS). Increased levels of diverse ROS are produced in the vessel wall and they individually or in combination may contribute to the pathogenesis of vascular disease. Thus, increased lipid peroxidation has been identified as a key mechanism for the development of atherosclerosis and inflammatory vascular damage. In fact, intracellular oxidative signals may induce the expression of a selective set of vascular inflammatory genes thus linking oxidative stress and inflammation in atherogenesis $[3,4]$.

Endothelial cells generate several protective mediators to regulate the functions of underlying vascular smooth muscle cells and circulating cells [5]. Among them, cyclooxygenase (COX)-2-dependent prostacyclin $\left(\mathrm{PGI}_{2}\right)$ plays a central role [5]. COX-2 is among endothelial genes upregulated by steady laminar shear stress (LSS) [6], which characterizes "atherosclerotic lesion-protected areas" [7]. COX activity of the enzyme catalyzes the conversion of free arachidonic acid to prostaglandin (PG) $\mathrm{G}_{2}$, which is then converted to $\mathrm{PGH}_{2}$ through its peroxidase activity [8]. Endothelial cells may transform $\mathrm{PGH}_{2}$ to a different array of the prostanoids (i.e., $\mathrm{PGD}_{2}, \mathrm{PGE}_{2}$, and $\mathrm{PGI}_{2}$ ) along the vascular beds; however, robust evidence sustains that $\mathrm{PGI}_{2}$ is the dominant 
prostanoid produced in the macrocirculation $[4,9]$. $\mathrm{PGI}_{2}$ exhibits properties of relevance to atheroprotection. In fact, it acts as a general restraint on endogenous stimuli to platelet activation, vascular proliferation and contraction, and cell adhesion [4]. It has been reported that $\mathrm{PGI}_{2}$ has antioxidant function before and in the early stage of atherogenesis through the induction of the antioxidant enzyme heme oxygenase (HO)-1 [10].

Recently, we provide evidence that COX-2-dependent $\mathrm{PGI}_{2}$ (induced by steady LSS) upregulates $\mathrm{HO}-1$, which halts the proatherogenic cytokine, tumor necrosis factor (TNF)- $\alpha$, in human endothelial cells [11]. Altogether, these data strongly support the key role of HO-1 pathway in the vasoprotective phenotype induced by $\mathrm{PGI}_{2}$.

In this paper we aim (i) to summarize the major features of the biology of HO-1 system by relating them to the role of this antioxidant enzyme in normal and pathological states, such as vascular inflammation and angiogenesis; (ii) to shed some light on the molecular mechanisms involved in the interplay between $\mathrm{HO}-1$ system and the vasoprotective $\mathrm{PGI}_{2}$.

\section{Biology of HO}

$\mathrm{HO}$ plays a central role in regulating the levels of intracellular heme by catalyzing the oxidative degradation of heme to liberate free iron, carbon monoxide (CO), and biliverdin in mammalian cells [20]. Biliverdin is metabolized to bilirubin by biliverdin reductase. Excess free heme catalyzes the formation of ROS, which leads to endothelial dysfunction as seen in numerous pathologic vascular conditions including systemic hypertension and diabetes, as well as in ischemia/reperfusion injury. The HO system, through its products, may cause different effects on the vascular system: (i) prevention of endothelial cell apoptosis; (ii) attenuation of the inflammatory response in the vessel wall; (iii) regulation of the vascular tone; (iv) participation in angiogenesis and vasculogenesis. Among all products of $\mathrm{HO}-1$, bilirubin and biliverdin are the most potent endogenous scavengers of ROS [21] and CO exerts antiapoptotic and anti-inflammatory effects through the induction of soluble guanylyl cyclase. It suppresses the production of TNF- $\alpha$, interleukin (IL)- $1 \beta$ and CCL4 chemokine (macrophage inflammatory protein$1 \beta)$ and induces the synthesis of anti-inflammatory IL10 [22]. Finally, free iron, despite participation in Fenton reaction that leads to formation of highly reactive hydroxyl radicals, activates Fe-ATPase. It is a transporter that removes intracellular iron as well as induces expression of ferritin heavy chains which sequester free iron and exert specific cytoprotective roles [23].

Three isoforms of $\mathrm{HO}$ have been described: an inducible isoform, HO-1, and two constitutively expressed isoforms, $\mathrm{HO}-2$ and $\mathrm{HO}-3 . \mathrm{HO}-1$ is a $32 \mathrm{kDa}$ microsomal protein considered to be a protective, early stress-response agent that may have additional nonenzymatic activities related to its mitochondrial localization and nuclear translocation. The expression of HO-1 is generally very low in normal tissues, apart from liver and spleen, where it participates in the processing of senescent or damaged erythrocytes and in protection against oxidative damage caused by free porphyrins [24]. In all tissues, low basal expression of HO-1 can be upregulated by a wide variety of stimuli that cause oxidative stress, including its substrate heme, heavy metals, cytokines, ultraviolet rays, lipopolysaccharide, hydrogen peroxide, growth factors, nitric oxide (NO), and also CO [25]. $\mathrm{HO}-2$, a $36-\mathrm{kDa}$ protein which is constitutively expressed, is localized primarily in the brain, testis, and vascular endothelium [26, 27]. Recently it has been postulated a novel role for HO-2 in the regulation of the inflammatory and reparative response to injury, which is a cytoprotective mechanism typically associated with $\mathrm{HO}-1$ induction. $\mathrm{HO}-2$ may constitute an essential protective circuit responsible of a basal tone of anti-inflammatory signals critical to the execution of self-resolving inflammatory-reparative processes [28]. HO-3, a lastly cloned $33-\mathrm{kDa}$ protein, which is a pseudogene derived from $\mathrm{HO}-2$ transcript, has been found only in rats [29].

\section{Regulation of HO-1 Gene Expression}

There are different mechanisms involved in the modulation of HO- 1 expression.

It has been reported that mitogen-activated protein kinases (MAPKs), phosphatidyl inositol 3-kinase/Akt, protein kinase (PK)A, PKC, and PKG [30], nuclear factor E2related factor 2 (Nrf2), Bach1 (bric-a-brac, tramtrack, and broad complex and cap " $\mathrm{n}$ " collar homology 1), activator protein-1 (AP-1), nuclear factor- $\kappa \mathrm{B}(\mathrm{NF}-\kappa \mathrm{B})$, cyclic adenosine monophosphate-responsive element-binding protein, and activating transcription factor 2 (ATF-2) [31] participate in $\mathrm{HO}-1$ gene regulation. The transcription factor Nrf2 plays a central role in the transcriptional activation of $\mathrm{HO}-1$ and many other genes encoding phase II drug-metabolizing enzymes in response to oxidative stress. Activation of $\mathrm{Nrf} 2$ is regulated by the cytosolic protein Keapl that negatively modulates the nuclear translocation of Nrf2 and facilitates degradation of $\mathrm{Nrf2}$ via the proteasome. Upon activation, Nrf2 enters the nucleus where it binds to the AU-rich elements (AREs) in the HO-1 promoter to trigger gene expression [17]. Nrf2 has been recently reported to regulate the induction of HO-1 in response to various forms of cellular stress, including hemodynamic, oxidative, and endoplasmic reticulum stress [32-34]. Moreover, fibroblasts and lung tissue from Nrf2-deficient animals express reduced levels of HO-1 [35, 36], further implicating Nrf2 in the induction of HO-1 [37].

Other transcription factors have been identified, such as the transcription factor Yin Yang (YY) 1 that is a downstream effector of $\mathrm{CO}$ produced by HO-1 [38] and hypoxiainducible factor (HIF)-1. It has been found that the increase in the transcription factor YY1 is involved in the inhibition of neointimal hyperplasia in vivo by HO-1 [38] and that the HIF-1 stabilization induces cardioprotection via HO-1 expression [39]. The results of Dawn and Bolli [39] show that HIF-1-mediated upregulation of HO-1 is beneficial to the ischemic myocardium.

In addition to the transcriptional regulation, it has been reported that a posttranslational mechanism may exist to 
attenuate $\mathrm{HO}-1$ expression. It has been demonstrated that two miRNAs, miR-217 and miR-377, combine to attenuate HO-1 protein expression, resulting in a significant reduction in HO-1 enzyme activity. The knockdown of both miR-217 and miR-377 increases HO-1 protein expression, while the overexpression of the same miRNAs leads to attenuation of protein expression [40]. Recently, Lin et al. show that HO-1 is subjected to posttranslational regulation by the ubiquitinproteasome system through an endoplasmic reticulumassociated degradation pathway [41]. Proteasome inhibition significantly decreased HO-1 protein degradation. Increased HO-1 expression by MG-132, a proteasome inhibitor, has been shown to protect astrocytes from heme-mediated oxidative injury [42].

\section{Polymorphisms in HO-1 Gene}

Three polymorphisms in the $5^{\prime}$ flanking region of the HO- 1 gene have been described: a (GT)n dinucleotide length polymorphism [43] and two single-nucleotide polymorphisms (SNPs), G(-1135)A and T(-413)A [44]. Only two, the (GT)n repeat polymorphism and the T(-413)A SNP, have been reported to exert functional importance by influencing the level of HO-1 expression in different organ systems. Thus, they may enhance or suppress the susceptibility to various disease conditions, including the maintenance of pregnancy $[44,45]$ and various cardiovascular (CV) disease [44].

In view of the apparently beneficial effects of placental HO-1 expression for the pregnancy outcome, the relationship between idiopathic recurrent miscarriage and a (GT)n repeat microsatellite polymorphism of HO-1 gene has been investigated [45]. The results from this study firstly showed the association between the HO-1 (GT)n microsatellite polymorphism in the human $\mathrm{HO}-1$ promoter regulatory region and women with idiopathic recurrent miscarriage in a relatively large Caucasian population, supporting the hypothesis that HO-1 polymorphisms among human population might contribute to some unexplained cases of pregnancy disorders, such as fetal growth retardation and preeclampsia [46].

$\mathrm{HO}-1$ plays a critical role in protecting the $\mathrm{CV}$ system from the damaging effects of oxidative stress. The two functional polymorphisms of HO-1 gene have been associated with $\mathrm{CV}$ disease and have different frequency distributions based upon ethnicity [44]. In particular, a significant association between the AA genotype of a T(-413)A polymorphism and arterial hypertension in Japanese women, but not in men, was observed [47]. This polymorphism was suggested to be associated with a higher expression of HO-1 and the authors suggest that an interaction between estrogeninduced expression of $\mathrm{NO}$ synthase and $\mathrm{HO}-1$-derived $\mathrm{CO}$, which attenuates $\mathrm{NO}$-induced vasodilation, may explain their findings [47]. However, the inconsistency between men and women raises some doubts on the reproducibility of these data. Moreover, the same authors demonstrated that the AA genotype of the $\mathrm{T}(-413) \mathrm{A}$ polymorphism may reduce the incidence of ischemic heart disease, even if it may potentially increase the risk of hypertension [48].
(GT)n dinucleotide repeat in the $\mathrm{HO}-1$ gene promoter shows a length polymorphism that modulates the level of gene transcription [43]. Compared with long (GT)n repeats, short (GT)n repeats in the human HO-1 gene promoter were shown to have higher transcriptional activity in response to oxidative stress [49]. It has been shown that length polymorphism in the $\mathrm{HO}-1$ gene promoter is related to coronary artery disease susceptibility in Japanese people, but this association was found only in patients with hypercholesterolemia or diabetes mellitus or in smokers [50], thus suggesting that HO-1 may play an antiatherogenic role in Japanese patients with these coronary risk factors.

Moreover, (GT)n microsatellite polymorphism was reported to be associated with emphysema, restenosis after percutaneous transluminal angioplasty, and coronary artery disease $[49,51,52]$. However, in some studies the association between $\mathrm{HO}-1$ polymorphisms and $\mathrm{CV}$ disease was not confirmed. A study based on a large number of 1807 patients showed that the (GT)n dinucleotide repeats length polymorphism located in the promoter region of the human HO-1 gene is not associated with the development of restenosis and major adverse clinical events following coronary stenting [53]. Similarly, Turpeinen et al. [54] showed that HO-1 gene polymorphisms have no significant role in outcome of kidney transplantation in the Finnish population. A recent prospective case-control study of more than 3000 participants showed that neither the (GT)n dinucleotide repeat nor the $\mathrm{T}(-413) \mathrm{A}$ polymorphism in the HO-1 promoter is associated with angiographic coronary artery disease, myocardial infarction, or survival rate in Caucasians undergoing coronary angiography [55]. Thus, altogether these studies leave still open the debate about the functional relevance of both variants of polymorphisms in HO-1 promoter. It is not unusual that studies of genetic polymorphisms produce divergent results, especially if small numbers of cases and controls are examined; often positive associations seen in small studies have been disproven in subsequent larger studies. In conclusion, even if the regulation of HO-1 gene may be determined, at least in part, by genetics, neither the (GT)n dinucleotide repeat nor the $\mathrm{T}(-413)$ A polymorphism of the HO-1 gene can be considered reliable genetic markers for $\mathrm{CV}$ disease.

\section{Role of HO-1 in Vascular Inflammation}

HO-1 represses inflammation by removing the proinflammatory molecule heme and by generating $\mathrm{CO}$ and the bile pigments, biliverdin, and bilirubin. These $\mathrm{HO}-1$ reaction products are capable of blocking innate and adaptive immune responses by modifying the activation, differentiation, maturation, and/or polarization of numerous cell types, including endothelial cells, monocytes/macrophages, dendritic cells, T lymphocytes, mast cells, and platelets. These cellular actions by $\mathrm{CO}$ and bile pigments result in diminished leukocyte recruitment and infiltration, and proinflammatory mediator production within atherosclerotic lesions [56].

The role of HO-1 in inflammation is demonstrated in HO-1 knockout mice, in which HO-1 deficiency leads to increased production of proinflammatory cytokines [57]. 
In patients subjected to bypass surgery, a higher activity of $\mathrm{HO}-1$ resulted in a lower concentration of IL-6 [58]. $\mathrm{HO}-1$ has been reported to reduce inflammatory cell rolling, adhesion, and migration from the vascular compartment, by downregulating the function and expression of adhesion molecules on the vessel wall $[59,60]$. In contrast, inhibition of HO-1 increases adhesion molecule expression [61-63].

Preclinical and clinical evidence clearly suggests that the progression of atherosclerosis is associated with inflammation [64]. Different studies have been performed to understand whether HO-1 can be protective in the pathogenesis of this disease. Experimental evidence demonstrates that the induction of HO-1 in vascular cells suppresses oxidized low-density-lipoprotein (LDL)-induced monocyte transmigration and inhibits atherosclerotic lesion formation in LDL receptor (LDLR) knockout mice $[65,66]$. Interestingly, the levels of bilirubin in the normal human population correlate inversely with the incidence of atherosclerotic events [67] and it has been shown that bilirubin attenuates vascular endothelial activation and dysfunction in vitro [12].

Recent interest has also focused on peroxisome proliferator-activated receptor $\delta(\operatorname{PPAR} \delta)$ ligands and induction of HO-1 expression. Ali et al. showed for the first time in vivo that $\mathrm{PPAR} \delta$ ligands induce vascular endothelial HO1 expression, thus supporting the hypothesis that PPAR $\delta$ represents an important potential target for the treatment of endothelial dysfunction and atherogenesis [13]. Finally, it has been shown that, in human monocytes, HO-1 activity is involved in attenuation of TNF- $\alpha$ production [68].

\section{Cross-Talk between HO-1 and PGI 2}

$\mathrm{PGI}_{2}$ is considered a major prostanoid generated in the macrocirculation (both in endothelial cells and vascular smooth muscle cells) $[5,9]$, where it inhibits platelet activation, vascular smooth muscle cell contraction and proliferation, leukocyte-endothelial cell interactions [69], and cholesteryl ester hydrolase and induces thrombomodulin, an important inhibitor of blood coagulation [70, 71]. $\mathrm{PGI}_{2}$ acts mostly through I prostanoid receptor (IP), a rhodopsinlike class A, 7-transmembrane-spanning G-protein-coupled receptor (GPCR), which activates membrane-bound adenylyl cyclase and the subsequent formation of the second messenger cyclic adenosine monophosphate (cAMP) [14]. Recently, studies in animal experimental models have shown that COX-2-derived $\mathrm{PGI}_{2}$ confers atheroprotection in female mice lacking the LDLR (an animal model of atherosclerosis), through the induction of HO-1 [10]. However, the possible contribution of endothelial COX-1 to $\mathrm{PGI}_{2}$ biosynthesis and of endothelial COX-2 to the generation of other prostanoids, in particular $\mathrm{PGE}_{2}$ [72], has not been completely clarified. In fact, recent results suggest a cardioprotective role of $\mathrm{PGE}_{2}$ via $\mathrm{E}$ prostanoid receptors (EP) 2 and $\mathrm{EP} 4[73,74]$; on the other hand, it is important to underline that $\mathrm{PGE}_{2}$, due its important role in inflammation, may enhance plaque burden and plaque destabilization in humans [75].

Thus, recently, we performed a study in human umbilical vein endothelial cells (HUVECs) exposed a physiological fluid mechanical stimulus in vitro [11] (Figure 1(a)) with the aims to (i) distinguish between the vasoprotective function of COX-2 and COX-1 and (ii) evaluate the contribution of different prostanoids to endothelial vasoprotection. In this study, we showed that in HUVECs exposed to uniform LSS of $10 \mathrm{dyn} / \mathrm{cm}^{2}$ (characteristically associated with lesionprotected areas), COX-2, but not COX-1 and downstream synthases, was significantly induced, and this translated into enhanced biosynthesis not only of $\mathrm{PGI}_{2}$, but also of other prostanoids, such as $\mathrm{PGE}_{2}$ and $\mathrm{PGD}_{2}$ (Figure $1(\mathrm{~b})$ ). Pharmacological studies, using a selective COX-2 inhibitor (NS398 ) and a nonselective COX inhibitor (aspirin), showed that both COX-2 and COX-1 contributed to $\mathrm{PGI}_{2}$ generation while only COX-1 contributed to $\mathrm{PGE}_{2}$ and $\mathrm{PGD}_{2}$. In the same study, we found that steady LSS reduces the synthesis and release of TNF- $\alpha$ (a known mediator of endothelial dysfunction and atherogenesis) [76, 77] from endothelial cells. Interestingly, we found that LSS-dependent reduction of TNF- $\alpha$ generation was completely countered by NS-398, aspirin, or the specific $\mathrm{PGI}_{2}$ receptor (IP) antagonist RO3244794 [78] (Figure 1(b)). Altogether, these results support the role of COX-2-dependent $\mathrm{PGI}_{2}$ in LSSdependent reduction of endothelial TNF- $\alpha$ generation. Since LSS induced the expression of $\mathrm{HO}-1$ and this effect was inhibited by NS-398, aspirin, or the IP antagonist, we hypothesized that the induction of $\mathrm{HO}-1$, as a consequence of COX-2-dependent $\mathrm{PGI}_{2}$ generation, is involved in LSSdependent reduction of endothelial TNF- $\alpha$ biosynthesis. This hypothesis was confirmed by the use of the novel imidazole-based HO-1 inhibitor QC15 [79]. In fact, we showed that the inhibition of HO-1 activity was associated with a complete abrogation of LSS-dependent inhibition of TNF- $\alpha$ biosynthesis (Figure 1(b)). Altogether these results support the contribution of LSS-induced $\mathrm{PGI}_{2}$ in the antiinflammatory effect of HO-1 in endothelial cells. This seems to be a novel protective action of endothelial $\mathrm{PGI}_{2}$ which may work in physiological conditions [11].

Further specific studies have to be performed to clarify the molecular pathways involved in the regulation of the vasoprotective gene $\mathrm{HO}-1$ by COX-2-dependent $\mathrm{PGI}_{2}$ in endothelial cells. We proposed that IP receptor signalling, through the activation of PKA, may induce the phosphorylation of glycogen synthase kinase (GSK)-3 [15], thus causing its inactivation and the loss of the capacity to phosphorylate Nrf2 [16]. This might translate into the stabilization of Nrf2 and its translocation into the nucleus, where it promotes the transcription of antioxidant and phase II genes, including HO-1 [11] (Figure 2). Furthermore, it has been shown that the Kruppel-like factor(KLF)-2 is increased in endothelial cells exposed to LSS [18]. This transcription factor may enhance antioxidant activity of Nrf2 by increasing its nuclear localization and activation [19]. The synergistic activity of the 2 transcription factors (Nrf2 and KLF-2) represents the major contribution to the shear-stress-elicited transcriptome in endothelial cells (Figure 2). Altogether our study provides evidence that COX-2-dependent $\mathrm{PGI}_{2}$ (induced by steady LSS) upregulates HO-1 which halts TNF- $\alpha$ generation in human endothelial cells [11]. This vasoprotective effect is abrogated by COX inhibitors, thus suggesting that inhibition of COX-2-dependent $\mathrm{PGI}_{2}$ might contribute to acceleration 


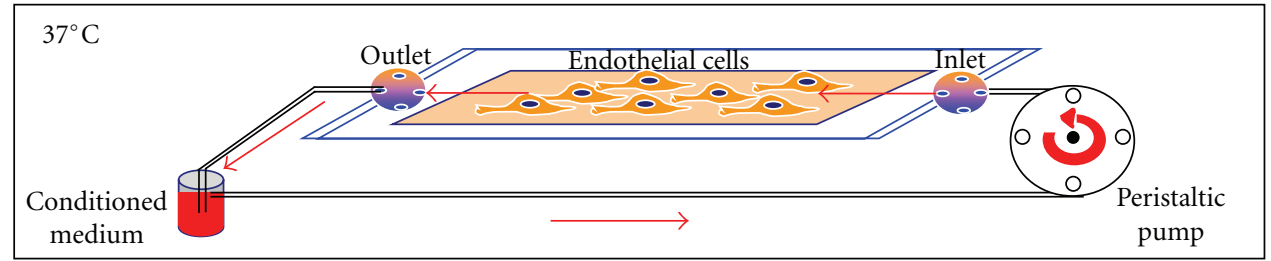

(a)

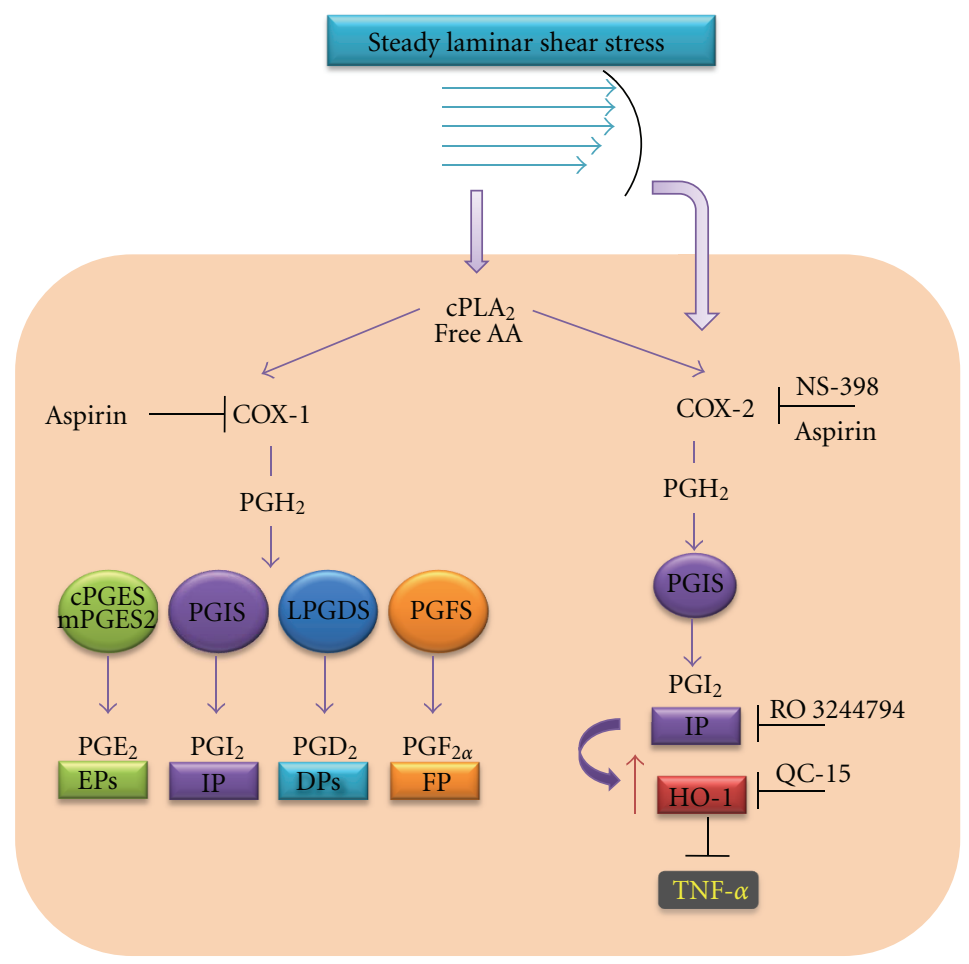

(b)

FIGURE 1: Exposure of endothelial cells to steady laminar shear stress (LSS). (a) HUVECs ( 0.8 to $1 \times 10^{6}$ cells per glass slide) are shear stressed using a parallel plate flow chamber connected to a constant pressure drop flow loop, maintained at $37^{\circ} \mathrm{C}$ and gassed continuously with a humidified mixture of $5 \% \mathrm{CO}_{2}$ in air. Endothelial monolayers are continuously perfused in a closed circuit at an estimated shear stress of $10 \mathrm{dyn} / \mathrm{cm}^{2}$ (flow rate of $2.53 \mathrm{~mL} / \mathrm{min}$; shear rate of $1400 \mathrm{sec}^{-1}$ ) with $7 \mathrm{~mL}$ of perfusion DMEM-medium 199 (50\% vol/vol), supplemented

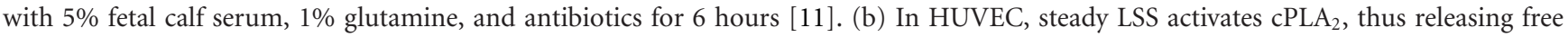
arachidonic acid (AA) from cell membrane phospholipids, the substrate of cyclooxygenase isoenzymes (COX-1 and COX-2). In addition, LSS upregulates COX-2 expression in HUVEC, without affecting the expression of COX-1 and downstream synthases (such as cPGES, mPGES2, PGIS, LPGDS, PGFS) [11]. Both COX-1 and COX-2 participate in the biosynthesis of $\mathrm{PGE}_{2}, \mathrm{PGI}_{2}, \mathrm{PGD}_{2}$, and $\mathrm{PGF}_{2 \alpha}$ as suggested by the finding that aspirin (a nonselective COX inhibitor) affects the levels of all these prostanoids. Differently, the selective COX-2 inhibitor (NS-398) affected only PGI 2 in HUVECs exposed to LSS which overexpressed COX-2. COX-2-dependent PGI 2 , induced by LSS, through the interaction with a specific receptor (IP), causes the induction of HO-1. It constrains TNF- $\alpha$ biosynthesis in HUVECs under this experimental condition. In fact, LSS-dependent reduction of TNF- $\alpha$ generation is completely countered by the selective COX-2 inhibitor NS-398, the nonselective COX inhibitor aspirin, or the specific $\mathrm{PGI}_{2}$ receptor (IP) antagonist RO3244794 [11, 12]. Finally, by the use of the novel imidazole-based HO-1 inhibitor QC15 [13], it has been shown that HO-1 induction in response to COX-dependent PGI 2 plays a role in LSS-dependent reduction of TNF- $\alpha$ biosynthesis [11].

of atherogenesis in patients taking traditional ( $\mathrm{t}$ ) nonsteroidal anti-inflammatory drugs (NSAIDs) and NSAIDs selective for COX-2 (coxibs).

\section{Role of HO-1 in Angiogenesis}

Angiogenesis involves the formation of new blood vessels and is critical for fundamental events such as development and repair after injury [80]. Recently, it has been shown that
HO- 1 and its gaseous product $\mathrm{CO}$ have potent proangiogenic properties in addition to well-recognized anti-inflammatory, antioxidant, and antiapoptotic effects [80]. Angiogenic factors, such as vascular endothelial growth factor (VEGF) and stromal cell-derived factor-1 (SDF-1), mediate their proangiogenic effects through induction of $\mathrm{HO}-1$, making it an attractive target for therapeutic intervention [80]. It has been reported that the role of $\mathrm{HO}-1$ in angiogenesis regulation could be "good" or "bad." The role of HO-1 in 


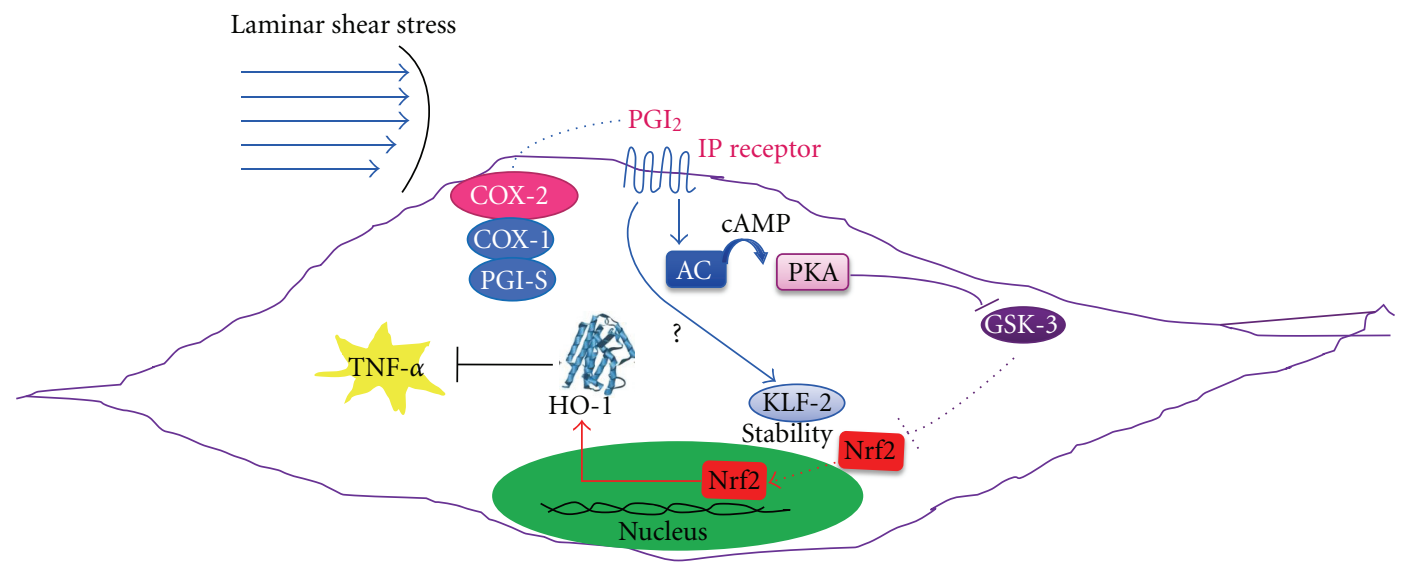

Figure 2: Postulated molecular mechanism involved in the induction of HO-1 by COX-2-dependent PGI 2 , in endothelial cells exposed to steady laminar shear stress (LSS). In endothelial cells exposed to uniform LSS (characteristically associated with atherosclerotic lesionprotected areas), COX-2 is overexpressed [11]. PGI $_{2}$, mainly produced by the combined activity of COX-2 and PGI - -synthase (PGIS), interacts with its specific receptor, IP [14]. This interaction may lead to the activation of adenylate cyclase (AC), causing an increase of intracellular levels of cyclic AMP (cAMP) and subsequently to the activation of protein kinase A (PKA) [14]. PKA may phosphorylate glycogen synthase kinase(GSK)-3 [15], causing its inactivation and the loss of the capacity to phosphorylate nuclear factor E2-related factor 2 (Nrf2) [16]. Reduced phosphorylation of Nrf2 causes its stabilization and translocation into the nucleus, where it promotes the transcription of antioxidant and phase II genes, including HO-1 [11, 17]. In addition to Nrf2, Kruppel-like factor(KLF)-2 is increased in endothelial cells exposed to LSS [18]. KLF2 enhances antioxidant activity of Nrf2 by increasing its nuclear localization and activation [19]. The synergistic activity of these two transcription factors forms a major contribution to the shear-stress-elicited transcriptome in endothelial cells. The overexpression of HO-1 in endothelial cells by LSS exerts an anti-inflammatory action through its capacity to inhibit the biosynthesis and release of TNF- $\alpha[11]$.

favoring angiogenesis responses is crucial for proper placental vascularization, wound healing, and neovascularization of ischemic heart. However, it may have detrimental outcomes in diseases where new blood vessel formation is undesirable, such as in tumor neovascularization [80].

Zhao and collaborators recently showed that a partial deficiency of maternal HO-1 resulted in the malformation of fetomaternal interface, alteration of the placental vasculature, insufficiency of spiral artery remodeling, and alteration of uterine natural killer cell differentiation and maturation [46]. These changes were independent of the fetal genotype, but relied on the maternal HO-1 level, which determined the balance of expression levels of pro- and antiangiogenic factors in the deciduas region [46]. According to these results a reduction in HO-1 placental expression was associated with recurrent miscarriages, spontaneous abortions, and preeclampsia [81]. These findings are in agreement with the results that HO-1 polymorphisms (as described above) are associated with idiopathic recurrent miscarriage in a relatively large Caucasian population of women [45].

The replacement of damaged capillaries and reestablishment of the normal oxygen amounts to a wound are accomplished by neovascularization. Wound-healing process includes a coagulation phase (characterized by endothelial dysfunction and platelet activation), an early extracellular matrix deposition, the release of factors by platelets, an inflammatory phase, and the resulting granulation, which are all events that rely on angiogenesis [82]. Growth factors including VEGF, chemokines like SDF-1, and hypoxiainducible factors (HIFs) also coordinate the multifaceted events involved in wound healing $[83,84]$. Interestingly, compared with wild-type littermate mice, HO-1-deficient mice exhibit impaired wound healing due, in part, to reduced recruitment of endothelial progenitor cells (EPCs) and capillary formation at the site of injury [85]. In addition, the induction of HO-1 in wounded skin was relatively weak and delayed in diabetic mice, in which also angiogenesis and wound closure were impaired. In such animals, local delivery of HO-1 transgene, using adenoviral vectors, accelerated the wound healing and increased the vascularization [86].

It has been recognized that $\mathrm{HO}-1$ has a protective effect in ischemic myocardium by the increasing of expression of angiogenic growth factors in the infarcted tissue [87]. VEGF is a strong therapeutic reagent by inducing angiogenesis in ischemic myocardium [88], and it can mediate the ischemiainduced mobilization of EPCs from bone marrow [89]. Lin et al. showed that HO-1 gene transfer after myocardial infarction provides protection at least in part by promoting angiogenesis through inducing angiogenic growth factors [90]. In addition, preclinical and clinical studies have demonstrated that mesenchymal stem cells (MSCs) transplantation can attenuate ventricular remodeling and augment cardiac function when implanted into the infarcted myocardium. In HO-1-transfected MSCs-treated hearts, the myocardial apoptosis was marked with significantly reduced fibrotic area and the cardiac function and remodeling were also significantly improved [87].

It is important to point out that in addition to the numerous lines of evidence supporting the positive role of HO-1 in angiogenesis regulation, several authors reported 
of the negative effects of this enzyme in tumor angiogenesis. In particular, it has been shown that several human tumors, including renal cell and prostate cancer, express high levels of HO-1 [91, 92]. HO-1 may promote tumor cell survival [93], hindering the effectiveness of anticancer therapies [94]. In contrast, inhibition of HO-1 has been shown to enhance tumor regression in animal models [95], suggesting that the HO-1 pathway may be a therapeutic target in carcinogenesis [80].

However, in prostatic cancer cells (PC3), HO-1 seems to be antiangiogenic. In fact, Ferrando et al. [96] identified a set of inflammatory and proangiogenic genes downregulated in response to $\mathrm{HO}-1$ overexpression, in particular VEGFA, VEGFC, HIF $1 \alpha$, and $\alpha 5 \beta 1$ integrin. An in vivo angiogenic assay showed that intradermal inoculation of PC3 cells stably transfected with HO-1 (PC3HO-1) generated tumors less vascularized than controls, with decreased microvessel density and reduced CD34 and MMP9 positive staining. Interestingly, longer-term grown $\mathrm{PC} 3 \mathrm{HO}-1$ xenografts displayed reduced neovascularization with the subsequent downregulation of VEGFR2 expression. Additionally, HO1 repressed NF- $\kappa \mathrm{B}$-mediated transcription, which strongly suggests that $\mathrm{HO}-1$ may regulate angiogenesis through this pathway. Taken together, these data support a key role of HO-1 as a modulator of the angiogenic switch in prostate carcinogenesis ascertaining it as a logical target for intervention therapy [96].

\section{Interplay between HO-1 and Estrogen}

Estrogen has both rapid and longer-term direct effects on CV tissues mediated by the two estrogen receptors, ER- $\alpha$ and ER- $\beta$ [97]. Estradiol promotes endothelial cell growth, protects endothelial cells against damage by oxidants and cholesterol, and induces the generation of endothelialderived vasodilators, such as $\mathrm{NO}$ and prostanoids [98]. In fact, premenopausal women are less susceptible to myocardial infarction and stroke than are males of the same age group, an advantage that is lost after menopause [99]. Several animal studies and some small clinical trials support a cardioprotective action of estrogens $[100,101] . \mathrm{E}_{2}$ retards atherogenesis in animal models [102] and improves endothelial disfunction in hyperlipidemic women [103].

Recently, Egan et al. [10] found that deletion of $\mathrm{PGI}_{2}$ receptor (IP) removes the atheroprotective effect of estrogen in ovariectomized female mice. The atheroprotective role of estrogen, in this setting, seems to be mediated by the induction of $\mathrm{PGI}_{2}$ biosynthesis. $\mathrm{PGI}_{2}$ activates its plasma membrane receptor IP which causes the induction of the antioxidant HO-1 in the vasculature. In fact, in vitro experiments, in mouse aortic smooth muscle cells (MASMCs), showed that estrogen acts on ER- $\alpha$ to upregulate the production of atheroprotective $\mathrm{PGI}_{2}$ through the induction of COX2 [10]. MASMCs lacking the $\mathrm{PGI}_{2}$ receptor $(\mathrm{IP} / \mathrm{KO})$ showed an increased oxidative stress suggesting that IP modulates oxidant stress under basal conditions. In addition, cicaprost, an IP agonist, increased HO-1 protein expression in wildtype MASMCs but not in IP/KO MASMCs. The involvement of IP signalling in the induction of vascular HO-1 was shown also in vivo. Thus, IP deletion decreased aortic HO-1 protein expression in female mice lacking both the IP and the LDL scavenger receptor (LDLR) (IP/LDLR DKO) [10]. These data showed that the atheroprotective role of estrogen is mediated by enhanced generation of COX-2-dependent $\mathrm{PGI}_{2}$ and suggest that chronic treatment of patients with NSAIDs selective for COX-2 (coxibs) or tNSAIDs could undermine the estrogen-mediated protection from CV disease in premenopausal females. A study was performed to estimate the interaction, in a general population setting (using information from the UK's General Practice Research Database), between tNSAIDs and hormone therapy on the occurrence of acute myocardial infarction and death from coronary heart disease [101]. The researchers found that current use of hormone replacement therapy was associated with a lower risk of heart attack than nonuse. However, when looking at women who used tNSAIDs at the same time as hormone replacement therapy, the researchers found no suggestion of a reduction in risk of heart attack. These findings suggest that hormone therapy and NSAIDs might interact, with NSAIDs acting against a role for hormone replacement therapy in preventing heart attacks. This pharmacodynamic interaction might play a role, at least in part, in the uncertain results regarding the effect of postmenopausal hormone therapy on heart disease in women [104].

\section{Cross-Talk between HO-1 and Cytochrome P-450-Derived Epoxyeicosatrienoic Acids}

A molecular crosstalk between the cytochrome P-450derived epoxyeicosatrienoic acids (EETs) and HO-1 gene expression was studied by Sacerdoti and coworkers [105, 106]. EETs induce HO-1 expression and signalling cascade [107], including activation of AMP-activated kinase (AMPK) and $\mathrm{pAKT}$, thus reducing adiposity and insulin resistance in animal model of obesity and diabetes. In addition, EETs decrease MSC-derived adipocyte stem cell differentiation by the upregulation of $\mathrm{HO}$-1-adiponectin-AKT signalling, suggesting that EET agonist may have potential therapeutic role in the treatment of dyslipidemia, diabetes, and the metabolic syndrome [108]. The potential action of EETs as intracellular lipid signalling modulators of adipogenesis was further supported by the recent finding that the treatment with EET agonists inhibits adipogenesis and decreases the levels of inflammatory cytokines. Interestingly, these effects are associated with the increase of $\mathrm{HO}-1$ expression, which occurs through the inhibition of a negative regulator of $\mathrm{HO}-$ 1 expression, Bach-1 [109].

\section{Conclusions and Perspectives}

Vascular health depends on a delicate balance in the vascular wall of prooxidative and antioxidant cellular mechanisms $[10,11]$. Several lines of evidence have shown that HO-1 plays a central role in the vasoprotection effects of $\mathrm{PGI}_{2}$. COX-2-dependent $\mathrm{PGI}_{2}$ (induced by steady LSS) upregulates HO- 1 which halts TNF- $\alpha$ generation in human endothelial cells [11]. Thus, clinical conditions associated with reduced 
generation of vascular $\mathrm{PGI}_{2}$ or the inhibition of COX-2dependent $\mathrm{PGI}_{2}$ by coxibs and tNSAIDs may cause $\mathrm{CV}$ hazard [5], at least in part, through downregulation of HO-1 expression. In fact, $\mathrm{HO}$ system could attenuate/block the progression of vascular diseases via its antioxidant, antiinflammatory, and antiproliferative effects.

Due to several beneficial effects of HO-1 for the CV system, it has emerged as a promising therapeutic target in the treatment of vascular disease. Pharmacological induction or gene transfer of HO-1 ameliorates vascular dysfunction in animal models of atherosclerosis, postangioplasty restenosis, vein graft stenosis, thrombosis, myocardial infarction, and hypertension, while inhibition of $\mathrm{HO}-1$ activity or gene deletion exacerbates these disorders [110].

Gene therapy and gene transfer, including site- and organ-specific targeted gene transfer have become powerful tools for studying the potential role of $\mathrm{HO}-1$ in the treatment of $\mathrm{CV}$ diseases. HO-1 induction by pharmacological agents or the in vitro gene transfer of human HO-1 into endothelial cells increases cell cycle progression and attenuates angiotensin II, TNF- $\alpha$, and heme-mediated DNA damage. In addition, administration of human $\mathrm{HO}-1$ to rats in advance of schemia/reperfusion injury considerably reduces tissue damage [111]. On the other hand, it should be point out that overexpression of human HO-1 may lead to some possible side effects. In particular, it may accelerate tumor growth, stimulates early stages of angiogenesis [80], increases the occurrence of metastasis and resistance to chemotherapy and photodynamic therapy [112].

Currently, gene therapy with the use of antioxidant genes, such as HO-1, is emerging as a promising approach for selecting CV pathologies, in particular for patient groups not suitable for conventional therapies [113]. However, in this area a further improvement of gene transfer vectors and transfer protocols to more efficiently transduce different cell types of the CV system is still required and diagnostic means for better identification of patients most likely to benefit from gene therapy interventions are lacking.

\section{Authors' Contribtion}

E. Marcantoni and L. di Francesco contributed equally to this paper.

\section{References}

[1] E. Bartoloni, Y. Shoenfeld, and R. Gerli, "Inflammatory and autoimmune mechanisms in the induction of atherosclerotic damage in systemic rheumatic diseases: two faces of the same coin," Arthritis Care and Research, vol. 63, no. 2, pp. 178-183, 2011.

[2] M. Gawaz, H. Langer, and A. E. May, "Platelets in inflammation and atherogenesis," Journal of Clinical Investigation, vol. 115, no. 12, pp. 3378-3384, 2005.

[3] K. K. Griendling and G. A. FitzGerald, "Oxidative stress and cardiovascular injury. Part I: basic mechanisms and in vivo monitoring of ROS," Circulation, vol. 108, no. 16, pp. 1912$1916,2003$.
[4] P. Minuz, C. Fava, and A. Lechi, "Lipid peroxidation, isoprostanes and vascular damage," Pharmacological Reports, vol. 58, pp. 57-68, 2006.

[5] T. Grosser, S. Fries, and G. A. FitzGerald, "Biological basis for the cardiovascular consequences of COX-2 inhibition: therapeutic challenges and opportunities," Journal of Clinical Investigation, vol. 116, no. 1, pp. 4-15, 2006.

[6] J. N. Topper, J. Cai, D. Falb, and M. A. Gimbrone, "Identification of vascular endothelial genes differentially responsive to fluid mechanical stimuli: cyclooxygenase-2, manganese superoxide dismutase, and endothelial cell nitric oxide synthase are selectively up-regulated by steady laminar shear stress," Proceedings of the National Academy of Sciences of the United States of America, vol. 93, no. 19, pp. 10417$10422,1996$.

[7] C. K. Zarins, D. P. Giddens, and B. K. Bharadvaj, "Carotid bifurcation atherosclerosis. Quantitative correlation of plaque localization with flow velocity profiles and wall shear stress," Circulation Research, vol. 53, no. 4, pp. 502-514, 1983.

[8] C. D. Funk, "Prostaglandins and leukotrienes: advances in eicosanoid biology," Science, vol. 294, no. 5548, pp. 18711875, 2001.

[9] S. Moncada, E. A. Higgs, and J. R. Vane, "Human arterial and venous tissues generate prostacyclin (prostaglandin X), a potent inhibitor of platelet aggregation," Lancet, vol. 1, no. 8001, pp. 18-21, 1977.

[10] K. M. Egan, J. A. Lawson, S. Fries et al., "COX-2-derived prostacyclin confers atheroprotection on female mice," Science, vol. 306, no. 5703, pp. 1954-1957, 2004.

[11] L. Di Francesco, L. Totani, M. Dovizio et al., "Induction of prostacyclin by steady laminar shear stress suppresses tumor necrosis factor- $\alpha$ biosynthesis via heme oxygenase- 1 in human endothelial cells," Circulation Research, vol. 104, no. 4, pp. 506-513, 2009.

[12] K. Kawamura, K. Ishikawa, Y. Wada et al., "Bilirubin from heme oxygenase-1 attenuates vascular endothelial activation and dysfunction," Arteriosclerosis, Thrombosis, and Vascular Biology, vol. 25, no. 1, pp. 155-160, 2005.

[13] F. Ali, N. S. Ali, A. Bauer et al., "PPAR $\sigma$ and PGC1 $\alpha$ act cooperatively to induce haem oxygenase-1 and enhance vascular endothelial cell resistance to stress," Cardiovascular Research, vol. 85, no. 4, pp. 701-710, 2010.

[14] S. Narumiya, Y. Sugimoto, and F. Ushikubi, "Prostanoid receptors: structures, properties, and functions," Physiological Reviews, vol. 79, no. 4, pp. 1193-1226, 1999.

[15] X. Fang, S. X. Yu, Y. Lu, R. C. Bast, J. R. Woodgett, and G. B. Mills, "Phosphorylation and inactivation of glycogen synthase kinase 3 by protein kinase A," Proceedings of the National Academy of Sciences of the United States of America, vol. 97, no. 22, pp. 11960-11965, 2000.

[16] M. Salazar, A. I. Rojo, D. Velasco, R. M. De Sagarra, and A. Cuadrado, "Glycogen synthase kinase- $3 \beta$ inhibits the xenobiotic and antioxidant cell response by direct phosphorylation and nuclear exclusion of the transcription factor Nrf2," Journal of Biological Chemistry, vol. 281, no. 21, pp. 1484114851, 2006.

[17] X. M. Liu, K. J. Peyton, D. Ensenat et al., "Nitric oxide stimulates heme oxygenase-1 gene transcription via the Nrf2/ARE complex to promote vascular smooth muscle cell survival," Cardiovascular Research, vol. 75, no. 2, pp. 381-389, 2007.

[18] S. SenBanerjee, Z. Lin, G. B. Atkins et al., "KLF2 is a novel transcriptional regulator of endothelial proinflammatory 
activation," Journal of Experimental Medicine, vol. 199, no. 10, pp. 1305-1315, 2004

[19] J. O. Fledderus, R. A. Boon, O. L. Volger et al., "KLF2 primes the antioxidant transcription factor Nrf2 for activation in endothelial cells," Arteriosclerosis, Thrombosis, and Vascular Biology, vol. 28, no. 7, pp. 1339-1346, 2008.

[20] N. G. Abraham and A. Kappas, "Pharmacological and clinical aspects of heme oxygenase," Pharmacological Reviews, vol. 60, no. 1, pp. 79-127, 2008.

[21] R. Stocker, Y. Yamamoto, and A. F. McDonagh, "Bilirubin is an antioxidant of possible physiological importance," Science, vol. 235, no. 4792, pp. 1043-1046, 1987.

[22] L. E. Otterbein, F. H. Bach, J. Alam et al., "Carbon monoxide has anti-inflammatory effects involving the mitogenactivated protein kinase pathway," Nature Medicine, vol. 6, no. 4, pp. 422-428, 2000.

[23] R. R. Crichton, S. Wilmet, R. Legssyer, and R. J. Ward, "Molecular and cellular mechanisms of iron homeostasis and toxicity in mammalian cells," Journal of Inorganic Biochemistry, vol. 91, no. 1, pp. 9-18, 2002.

[24] R. Tenhunen, H. S. Marver, and R. Schmid, "The enzymatic conversion of heme to bilirubin by microsomal heme oxygenase," Proceedings of the National Academy of Sciences of the United States of America, vol. 61, no. 2, pp. 748-755, 1968.

[25] S. W. Ryter, J. Alam, and A. M. K. Choi, "Heme oxygenase$1 /$ carbon monoxide: from basic science to therapeutic applications," Physiological Reviews, vol. 86, no. 2, pp. 583-650, 2006.

[26] N. G. Abraham, G. S. Drummond, J. D. Lutton, and A. Kappas, "The biological significance and physiological role of heme oxygenase," Cellular Physiology and Biochemistry, vol. 6, no. 3, pp. 129-168, 1996.

[27] W. K. McCoubrey Jr., J. F. Ewing, and M. D. Maines, "Human heme oxygenase-2: Characterization and expression of a fulllength cDNA and evidence suggesting that the two HO-2 transcripts may differ by choice of polyadenylation signal," Archives of Biochemistry and Biophysics, vol. 295, no. 1, pp. 13-20, 1992.

[28] F. Seta, L. Bellner, R. Rezzani et al., "Heme oxygenase-2 is a critical determinant for execution of an acute inflammatory and reparative response," American Journal of Pathology, vol. 169, no. 5, pp. 1612-1623, 2006.

[29] W. K. Mccoubrey Jr., T. J. Huang, and M. D. Maines, "Isolation and characterization of a cDNA from the rat brain that encodes hemoprotein heme oxygenase-3," European Journal of Biochemistry, vol. 247, no. 2, pp. 725-732, 1997.

[30] R. Stocker and M. A. Perrella, "Heme oxygenase-1: a novel drug target for atherosclerotic diseases?" Circulation, vol. 114, no. 20, pp. 2178-2189, 2006.

[31] Y. M. Kim, H. O. Pae, J. E. Park et al., "Heme oxygenase in the regulation of vascular biology: from molecular mechanisms to therapeutic opportunities," Antioxidants and Redox Signaling, vol. 14, no. 1, pp. 137-167, 2011.

[32] X. L. Chen, S. E. Varner, A. S. Rao et al., "Laminar flow induction of antioxidant response element-mediated genes in endothelial cells: a novel anti-inflammatory mechanism," Journal of Biological Chemistry, vol. 278, no. 2, pp. 703-711, 2003.

[33] T. Ishii, K. Itoh, E. Ruiz et al., "Role of Nrf2 in the regulation of $\mathrm{CD} 36$ and stress protein expression in murine macrophages: activation by oxidatively modified LDL and 4-hydroxynonenal," Circulation Research, vol. 94, no. 5, pp. 609-616, 2004.
[34] X. M. Liu, K. J. Peyton, D. Ensenat et al., "Endoplasmic reticulum stress stimulates heme oxygenase-1 gene expression in vascular smooth muscle: role in cell survival," Journal of Biological Chemistry, vol. 280, no. 2, pp. 872-877, 2005.

[35] L. Leung, M. Kwong, S. Hou, C. Lee, and J. Y. Chan, "Deficiency of the Nrf1 and Nrf2 transcription factors results in early embryonic lethality and severe oxidative stress," Journal of Biological Chemistry, vol. 278, no. 48, pp. 4802148029, 2003.

[36] H. Y. Cho, A. E. Jedlicka, S. P. M. Reddy et al., "Role of NRF2 in protection against hyperoxic lung injury in mice," American Journal of Respiratory Cell and Molecular Biology, vol. 26, no. 2, pp. 175-182, 2002.

[37] X. M. Liu, K. J. Peyton, D. Ensenat et al., "Nitric oxide stimulates heme oxygenase-1 gene transcription via the Nrf2/ARE complex to promote vascular smooth muscle cell survival," Cardiovascular Research, vol. 75, no. 2, pp. 381-389, 2007.

[38] K. Beck, B. J. Wu, J. Ni et al., "Interplay between heme oxygenase-1 and the multifunctional transcription factor Yin Yang 1 in the inhibition of intimal hyperplasia," Circulation Research, vol. 107, no. 12, pp. 1490-1497, 2010.

[39] B. Dawn and R. Bolli, "HO-1 induction by HIF-1: a new mechanism for delayed cardioprotection?" American Journal of Physiology, vol. 289, no. 2, pp. H522-H524, 2005.

[40] J. D. Beckman, C. Chen, J. Nguyen et al., "Regulation of heme oxygenase-1 protein expression by miR-377 in Combination with miR-217," Journal of Biological Chemistry, vol. 286, no. 5, pp. 3194-3202, 2011.

[41] P. H. Lin, M. T. Chiang, and L. Y. Chau, "Ubiquitinproteasome system mediates heme oxygenase-1 degradation through endoplasmic reticulum-associated degradation pathway," Biochimica et Biophysica Acta, vol. 1783, no. 10, pp. 1826-1834, 2008.

[42] J. Chen and R. F. Regan, "Increasing expression of heme oxygenase- 1 by proteasome inhibition protects astrocytes from heme-mediated oxidative injury," Current Neurovascular Research, vol. 2, no. 3, pp. 189-196, 2005.

[43] T. Kimpara, A. Takeda, K. Watanabe et al., "Microsatellite polymorphism in the human heme oxygenase-1 gene promoter and its application in association studies with Alzheimer and Parkinson disease," Human Genetics, vol. 100, no. 1, pp. 145-147, 1997.

[44] M. Exner, E. Minar, O. Wagner, and M. Schillinger, “The role of heme oxygenase-1 promoter polymorphisms in human disease," Free Radical Biology and Medicine, vol. 37, no. 8, pp. 1097-1104, 2004.

[45] D. Denschlag, R. Marculescu, G. Unfried et al., "The size of a microsatellite polymorphism of the haem oxygenase 1 gene is associated with idiopathic recurrent miscarriage," Molecular Human Reproduction, vol. 10, no. 3, pp. 211-214, 2004.

[46] H. Zhao, J. Azuma, F. Kalish, R. J. Wong, and D. K. Stevenson, "Maternal heme oxygenase 1 regulates placental vasculature development via angiogenic factors in mice," Biology of Reproduction, vol. 85, no. 5, pp. 1005-1012, 2011.

[47] K. Ono, T. Mannami, and N. Iwai, "Association of a promoter variant of the haeme oxygenase-1 gene with hypertension in women," Journal of Hypertension, vol. 21, no. 8, pp. 14971503, 2003.

[48] K. Ono, Y. Goto, S. Takagi et al., "A promoter variant of the heme oxygenase-1 gene may reduce the incidence of ischemic heart disease in Japanese," Atherosclerosis, vol. 173, no. 2, pp. 315-319, 2004. 
[49] N. Yamada, M. Yamaya, S. Okinaga et al., "Microsatellite polymorphism in the heme oxygenase-1 gene promoter is associated with susceptibility to emphysema," American Journal of Human Genetics, vol. 66, no. 1, pp. 187-195, 2000.

[50] H. Kaneda, M. Ohno, J. Taguchi et al., "Heme oxygenase1 gene promoter polymorphism is associated with coronary artery disease in Japanese patients with coronary risk factors," Arteriosclerosis, Thrombosis, and Vascular Biology, vol. 22, no. 10, pp. 1680-1685, 2002.

[51] M. Exner, M. Schillinger, E. Minar et al., "Heme oxygenase1 gene promoter microsatellite polymorphism is associated with restenosis after percutaneous transluminal angioplasty," Journal of Endovascular Therapy, vol. 8, no. 5, pp. 433-440, 2001.

[52] M. Schillinger, M. Exner, E. Minar et al., "Heme oxygenase1 genotype and restenosis after balloon angioplasty: a novel vascular protective factor," Journal of the American College of Cardiology, vol. 43, no. 6, pp. 950-957, 2004.

[53] K. Tiroch, W. Koch, N. Von Beckerath, A. Kastrati, and A. Schömig, "Heme oxygenase-1 gene promoter polymorphism and restenosis following coronary stenting," European Heart Journal, vol. 28, no. 8, pp. 968-973, 2007.

[54] H. Turpeinen, L. E. Kyllönen, J. Parkkinen, J. Laine, K. T. Salmela, and J. Partanen, "Heme oxygenase 1 gene polymorphisms and outcome of renal transplantation," International Journal of Immunogenetics, vol. 34, no. 4, pp. 253-257, 2007.

[55] N. Lüblinghoff, K. Winkler, B. R. Winkelmann et al., "Genetic variants of the promoter of the heme oxygenase- 1 gene and their influence on cardiovascular disease (The Ludwigshafen Risk and Cardiovascular Health Study)," BMC Medical Genetics, vol. 10, article no. 36, 2009.

[56] W. Durante, "Protective role of heme oxygenase-1 against inflammation in atherosclerosis," Frontiers in Bioscience, vol. 16, no. 6, pp. 2372-2388, 2011.

[57] M. H. Kapturczak, C. Wasserfall, T. Brusko et al., "Heme oxygenase-1 modulates early inflammatory responses: evidence from the heme oxygenase-1-deficient mouse," American Journal of Pathology, vol. 165, no. 3, pp. 1045-1053, 2004.

[58] H. Taha, K. Skrzypek, I. Guevara et al., "Role of heme oxygenase-1 in human endothelial cells: lesson from the promoter allelic variants," Arteriosclerosis, Thrombosis, and Vascular Biology, vol. 30, no. 8, pp. 1634-1641, 2010.

[59] F. A. D. T. G. Wagener, J. L. Da Silva, T. Farley, T. De Witte, A. Kappas, and N. G. Abraham, "Differential effects of heme oxygenase isoforms on heme mediation of endothelial intracellular adhesion molecule expression," Journal of Pharmacology and Experimental Therapeutics, vol. 291, no. 1, pp. 416-423, 1999.

[60] F. A. D. T. G. Wagener, A. Eggert, O. C. Boerman et al., "Heme is a potent inducer of inflammation in mice and is counteracted by heme oxygenase," Blood, vol. 98, no. 6, pp. 1802-1811, 2001.

[61] S. Hayashi, R. Takamiya, T. Yamaguchi et al., "Induction of heme oxygenase-1 suppresses venular leukocyte adhesion elicited by oxidative stress: role of bilirubin generated by the enzyme," Circulation Research, vol. 85, no. 8, pp. 663-671, 1999.

[62] T. J. Vachharajani, J. Work, A. C. Issekutz, and D. N. Granger, "Heme oxygenase modulates selectin expression in different regional vascular beds," American Journal of Physiology, vol. 278, no. 5, pp. H1613-H1617, 2000.

[63] J. D. Belcher, H. Mahaseth, T. E. Welch, L. E. Otterbein, R. P. Hebbel, and G. M. Vercellotti, "Heme oxygenase- 1 is a modulator of inflammation and vaso-occlusion in transgenic sickle mice," Journal of Clinical Investigation, vol. 116, no. 3, pp. 808-816, 2006.

[64] P. Libby, Y. Okamoto, V. Z. Rocha, and E. Folco, "Inflammation in atherosclerosis: transition from theory to practice," Circulation Journal, vol. 74, no. 2, pp. 213-220, 2010.

[65] K. Ishikawa, M. Navab, N. Leitinger, A. M. Fogelman, and A. J. Lusis, "Induction of heme oxygenase-1 inhibits the monocyte transmigration induced by mildly oxidized LDL," Journal of Clinical Investigation, vol. 100, no. 5, pp. 12091216, 1997.

[66] K. Ishikawa, D. Sugawara, X. P. Wang et al., "Heme oxygenase-1 inhibits atherosclerotic lesion formation in LDL-receptor knockout mice," Circulation Research, vol. 88, no. 5, pp. 506-512, 2001.

[67] M. Mayer, "Association of serum bilirubin concentration with risk of coronary artery disease," Clinical Chemistry, vol. 46, no. 11, pp. 1723-1727, 2000.

[68] Y. Drechsler, A. Dolganiuc, O. Norkina et al., "Heme oxygena-1 mediates the anti-inflammatory effects of acute alcohol on IL-10 induction involving p38 MAPK activation in monocytes," Journal of Immunology, vol. 177, no. 4, pp. 2592-2600, 2006.

[69] T. Kobayashi, Y. Tahara, M. Matsumoto et al., "Roles of thromboxane $\mathrm{A}_{2}$ and prostacyclin in the development of atherosclerosis in apoE-deficient mice," Journal of Clinical Investigation, vol. 114, no. 6, pp. 784-794, 2004.

[70] S. Moncada, R. Gryglewski, S. Bunting, and J. R. Vane, "An enzyme isolated from arteries transforms prostaglandin endoperoxides to an unstable substance that inhibits platelet aggregation," Nature, vol. 263, no. 5579, pp. 663-665, 1976.

[71] K. Rabausch, E. Bretschneider, M. Sarbia et al., "Regulation of thrombomodulin expression in human vascular smooth muscle cells by COX-2-derived prostaglandins," Circulation research, vol. 96, no. 1, pp. e1-e6, 2005.

[72] D. W. Kawka, M. Ouellet, P. O. Hétu, I. I. Singer, and D. Riendeau, "Double-label expression studies of prostacyclin synthase, thromboxane synthase and COX isoforms in normal aortic endothelium," Biochimica et Biophysica Acta, vol. 1771, no. 1, pp. 45-54, 2007.

[73] C. R. J. Kennedy, Y. Zhang, S. Brandon et al., "Saltsensitive hypertension and reduced fertility in mice lacking the prostaglandin EP2 receptor," Nature Medicine, vol. 5, no. 2, pp. 217-220, 1999.

[74] A. M. Hristovska, L. E. Rasmussen, P. B. L. Hansen et al., "Prostaglandin $\mathrm{E}_{2}$ induces vascular relaxation by $\mathrm{E}$ prostanoid 4 receptor-mediated activation of endothelial nitric oxide synthase," Hypertension, vol. 50, no. 3, pp. 525530, 2007.

[75] U. T. Shankavaram, W. C. Lai, S. Netzel-Arnett et al., "Monocyte membrane type 1-matrix metalloproteinase: prostaglandin-dependent regulation and role in metalloproteinase-2 activation," Journal of Biological Chemistry, vol. 276, no. 22, pp. 19027-19032, 2001.

[76] P. Barath, M. C. Fishbein, J. Cao, J. Berenson, R. H. Helfant, and J. S. Forrester, "Detection and localization of tumor necrosis factor in human atheroma," American Journal of Cardiology, vol. 65, no. 5, pp. 297-302, 1990.

[77] C. Cardillo, F. Schinzari, N. Mores et al., "Intravascular tumor necrosis factor $\alpha$ blockade reverses endothelial dysfunction in rheumatoid arthritis," Clinical Pharmacology and Therapeutics, vol. 80, no. 3, pp. 275-281, 2006.

[78] K. R. Bley, A. Bhattacharya, D. V. Daniels et al., "RO1138452 and RO3244794: characterization of structurally distinct, 
potent and selective IP (prostacyclin) receptor antagonists," British Journal of Pharmacology, vol. 147, no. 3, pp. 335-345, 2006.

[79] R. T. Kinobe, Y. Ji, J. Z. Vlahakis et al., "Effectiveness of novel imidazole-dioxolane heme oxygenase inhibitors in renal proximal tubule epithelial cells," Journal of Pharmacology and Experimental Therapeutics, vol. 323, no. 3, pp. 763-770, 2007.

[80] J. Dulak, J. Deshane, A. Jozkowicz, and A. Agarwal, "Heme oxygenase- 1 and carbon monoxide in vascular pathobiology: focus on angiogenesis," Circulation, vol. 117, no. 2, pp. 231241, 2008.

[81] F. Lyall and L. Myatt, "The role of the placenta in preeclampsia-a workshop report," Placenta, vol. 23, no. 1, pp. S142-S145, 2002.

[82] S. M. Bauer, R. J. Bauer, and O. C. Velazquez, "Angiogenesis, vasculogenesis, and induction of healing in chronic wounds," Vascular and Endovascular Surgery, vol. 39, no. 4, pp. 293306, 2005.

[83] D. J. Ceradini, A. R. Kulkarni, M. J. Callaghan et al., "Progenitor cell trafficking is regulated by hypoxic gradients through HIF-1 induction of SDF-1," Nature Medicine, vol. 10, no. 8, pp. 858-864, 2004.

[84] O. M. Tepper, J. M. Capla, R. D. Galiano et al., "Adult vasculogenesis occurs through in situ recruitment, proliferation, and tubulization of circulating bone marrow-derived cells," Blood, vol. 105, no. 3, pp. 1068-1077, 2005.

[85] J. Deshane, S. Chen, S. Caballero et al., "Stromal cell-derived factor 1 promotes angiogenesis via a heme oxygenase 1dependent mechanism," Journal of Experimental Medicine, vol. 204, no. 3, pp. 605-618, 2007.

[86] A. Grochot-Przeczek, R. Lach, J. Mis et al., "Heme oxygenase1 accelerates cutaneous wound healing in mice," PLoS One, vol. 4, no. 6, Article ID e5803, 2009.

[87] B. Zeng, G. Lin, X. Ren, Y. Zhang, and H. Chen, "Overexpression of HO-1 on mesenchymal stem cells promotes angiogenesis and improves myocardial function in infarcted myocardium," Journal of Biomedical Science, vol. 17, no. 1, article no. 80, 2010.

[88] H. Huwer, C. Welter, C. Özbek et al., "Simultaneous surgical revascularization and angiogenic gene therapy in diffuse coronary artery disease," European Journal of Cardio-thoracic Surgery, vol. 20, no. 6, pp. 1128-1134, 2001.

[89] O. Jeon, S. J. Song, S. H. Bhang, C. Y. Choi, M. J. Kim, and B. S. Kim, "Additive effect of endothelial progenitor cell mobilization and bone marrow mononuclear cell transplantation on angiogenesis in mouse ischemic limbs," Journal of Biomedical Science, vol. 14, no. 3, pp. 323-330, 2007.

[90] H. H. Lin, Y. H. Chen, P. F. Chang, Y. T. Lee, S. F. Yet, and L. Y. Chau, "Heme oxygenase-1 promotes neovascularization in ischemic heart by coinduction of VEGF and SDF-1," Journal of Molecular and Cellular Cardiology, vol. 45, no. 1, pp. 44-55, 2008.

[91] A. I. Goodman, M. Choudhury, J. L. Da Silva, M. L. Schwartzman, and N. G. Abraham, "Overexpression of the heme oxygenase gene in renal cell carcinoma," Proceedings of the Society for Experimental Biology and Medicine, vol. 214, no. 1, pp. 54-61, 1997.

[92] M. D. Maines and P. A. Abrahamsson, "Expression of heme oxygenase-1 (HSP32) in human prostate: normal, hyperplastic, and tumor tissue distribution," Urology, vol. 47, no. 5, pp. 727-733, 1996.

[93] H. Was, T. Cichon, R. Smolarczyk et al., "Overexpression of heme oxygenase- 1 in murine melanoma: increased proliferation and viability of tumor cells, decreased survival of mice,"
American Journal of Pathology, vol. 169, no. 6, pp. 2181-2198, 2006.

[94] D. Nowis, M. Legat, T. Grzela et al., "Heme oxygenase-1 protects tumor cells against photodynamic therapy-mediated cytotoxicity," Oncogene, vol. 25, no. 24, pp. 3365-3374, 2006.

[95] J. Fang, T. Sawa, T. Akaike et al., "In vivo antitumor activity of pegylated zinc protoporphyrin: targeted inhibition of heme oxygenase in solid tumor," Cancer Research, vol. 63, no. 13, pp. 3567-3574, 2003.

[96] M. Ferrando, G. Gueron, B. Elguero et al., "Heme oxygenase 1 (HO-1) challenges the angiogenic switch in prostate cancer," Angiogenesis, vol. 14, no. 4, pp. 467-479, 2011.

[97] M. E. Mendelsohn and R. H. Karas, "The protective effects of estrogen on the cardiovascular system," New England Journal of Medicine, vol. 340, no. 23, pp. 1801-1811, 1999.

[98] M. Rosselli, B. Imthurn, P. J. Keller, E. K. Jackson, and R. K. Dubey, "Circulating nitric oxide (nitrite/nitrate) levels in postmenopausal women substituted with $17 \beta$-estradiol and norethisterone acetate: a two-year follow-up study," Hypertension, vol. 25, no. 4, pp. 848-853, 1995.

[99] M. E. Mendelsohn, "Protective effects of estrogen on the cardiovascular system," American Journal of Cardiology, vol. 89, no. 12, pp. 12E-18E, 2002.

[100] R. K. Dubey, B. Imthurn, M. Barton, and E. K. Jackson, "Vascular consequences of menopause and hormone therapy: importance of timing of treatment and type of estrogen," Cardiovascular Research, vol. 66, no. 2, pp. 295-306, 2005.

[101] L. A. García Rodríguez, K. Egan, and G. A. FitzGerald, "Traditional nonsteroidal anti-inflammatory drugs and postmenopausal hormone therapy: a drug-drug interaction?" PLoS Medicine, vol. 4, no. 5, article e157, 2007.

[102] P. A. K. Bourassa, P. M. Milos, B. J. Gaynor, J. L. Breslow, and R. J. Aiello, "Estrogen reduces atherosclerotic lesion development in apolipoprotein E-deficient mice," Proceedings of the National Academy of Sciences of the United States of America, vol. 93, no. 19, pp. 10022-10027, 1996.

[103] P. Collins, G. M. C. Rosano, P. M. Sarrel et al., “ $17 \beta-$ estradiol attenuates acetylcholine-induced coronary arterial constriction in women but not men with coronary heart disease," Circulation, vol. 92, no. 1, pp. 24-30, 1995.

[104] G. M. C. Rosano, C. Vitale, A. Silvestri, and M. Fini, "Hormone replacement therapy and cardioprotection: the end of the tale?" Annals of the New York Academy of Sciences, vol. 997, pp. 351-357, 2003.

[105] D. Sacerdoti, M. Bolognesi, M. Di Pascoli et al., "Rat mesenteric arterial dilator response to 11,12-epoxyeicosatrienoic acid is mediated by activating heme oxygenase," American Journal of Physiology, vol. 291, no. 4, pp. H1999-H2002, 2006.

[106] D. Sacerdoti, C. Colombrita, M. Di Pascoli et al., "11,12Epoxyeicosatrienoic acid stimulates heme-oxygenase-1 in endothelial cells," Prostaglandins and Other Lipid Mediators, vol. 82, no. 1-4, pp. 155-161, 2007.

[107] K. Sodhi, K. Inoue, K. H. Gotlinger et al., "Epoxyeicosatrienoic acid agonist rescues the metabolic syndrome phenotype of HO-2-null mice," Journal of Pharmacology and Experimental Therapeutics, vol. 331, no. 3, pp. 906-916, 2009.

[108] D. H. Kim, L. Vanella, K. Inoue et al., "Epoxyeicosatrienoic acid agonist regulates human mesenchymal stem cell-derived adipocytes through activation of HO-1-pAKT signaling and a decrease in PPARy," Stem Cells and Development, vol. 19, no. 12, pp. 1863-1873, 2010.

[109] L. Vanella, D. H. Kim, K. Sodhi et al., "Crosstalk between EET and HO-1 downregulates Bach1 and adipogenic marker 
expression in mesenchymal stem cell derived adipocytes," Prostaglandins and Other Lipid Mediators, vol. 96, no. 1-4, pp. 54-62, 2011.

[110] W. Durante, "Targeting heme oxygenase-1 in vascular disease," Current drug targets, vol. 11, no. 12, pp. 1504-1516, 2010.

[111] S. J. Peterson and W. H. Frishman, "Targeting heme oxygenase: therapeutic implications for diseases of the cardiovascular system," Cardiology in Review, vol. 17, no. 3, pp. 99-111, 2009.

[112] S. Tanaka, T. Akaike, J. Fang et al., "Antiapoptotic effect of haem oxygenase-1 induced by nitric oxide in experimental solid tumour," British Journal of Cancer, vol. 88, no. 6, pp. 902-909, 2003.

[113] A. L. Levonen, E. Vähäkangas, J. K. Koponen, and S. Ylä-Herttuala, "Antioxidant gene therapy for cardiovascular disease: current status and future perspectives," Circulation, vol. 117, no. 16, pp. 2142-2150, 2008. 


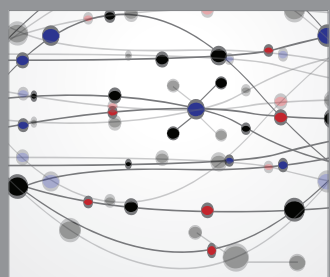

The Scientific World Journal
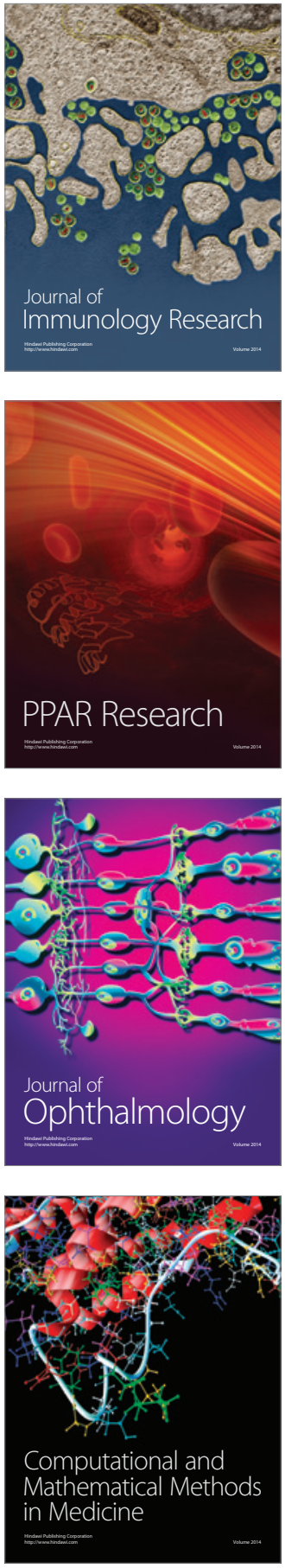

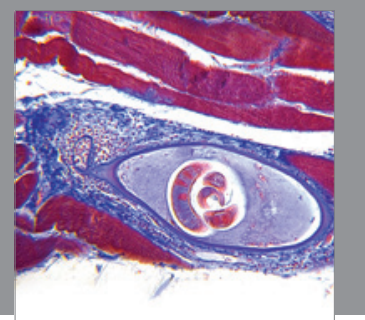

Gastroenterology

Research and Practice
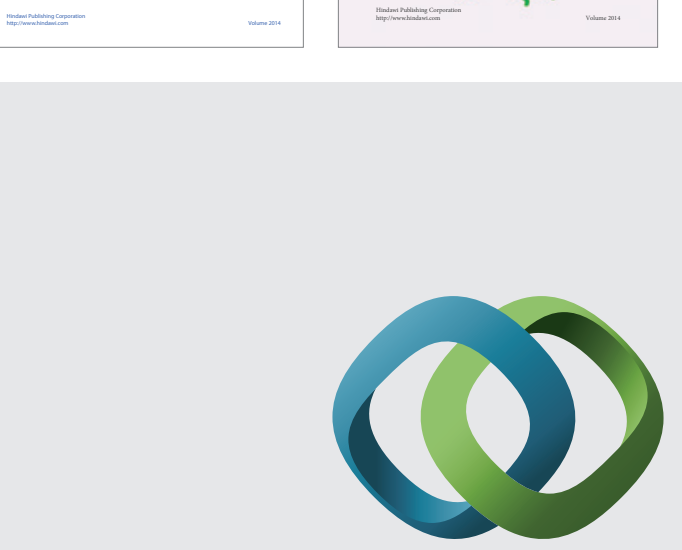

\section{Hindawi}

Submit your manuscripts at

http://www.hindawi.com
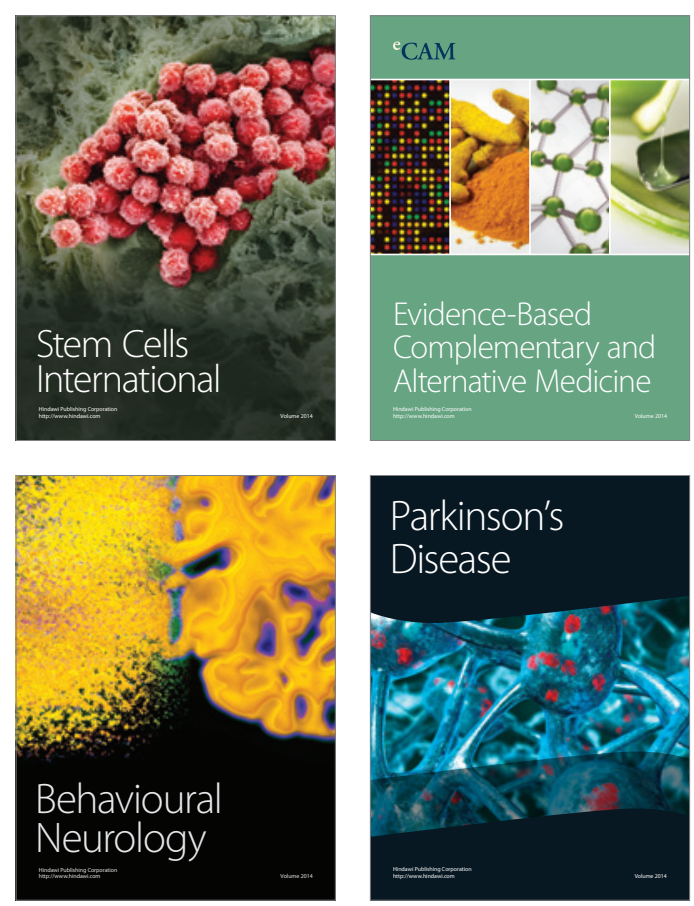

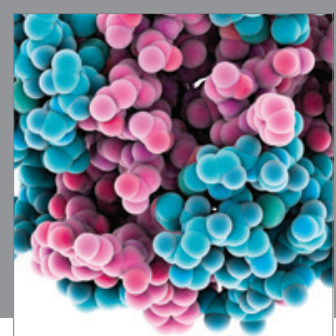

Journal of
Diabetes Research

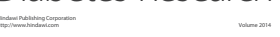

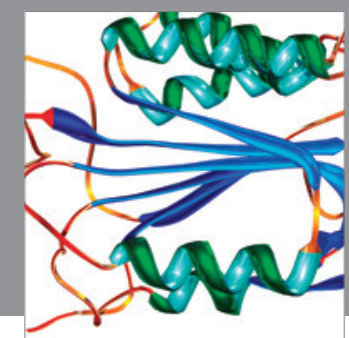

Disease Markers
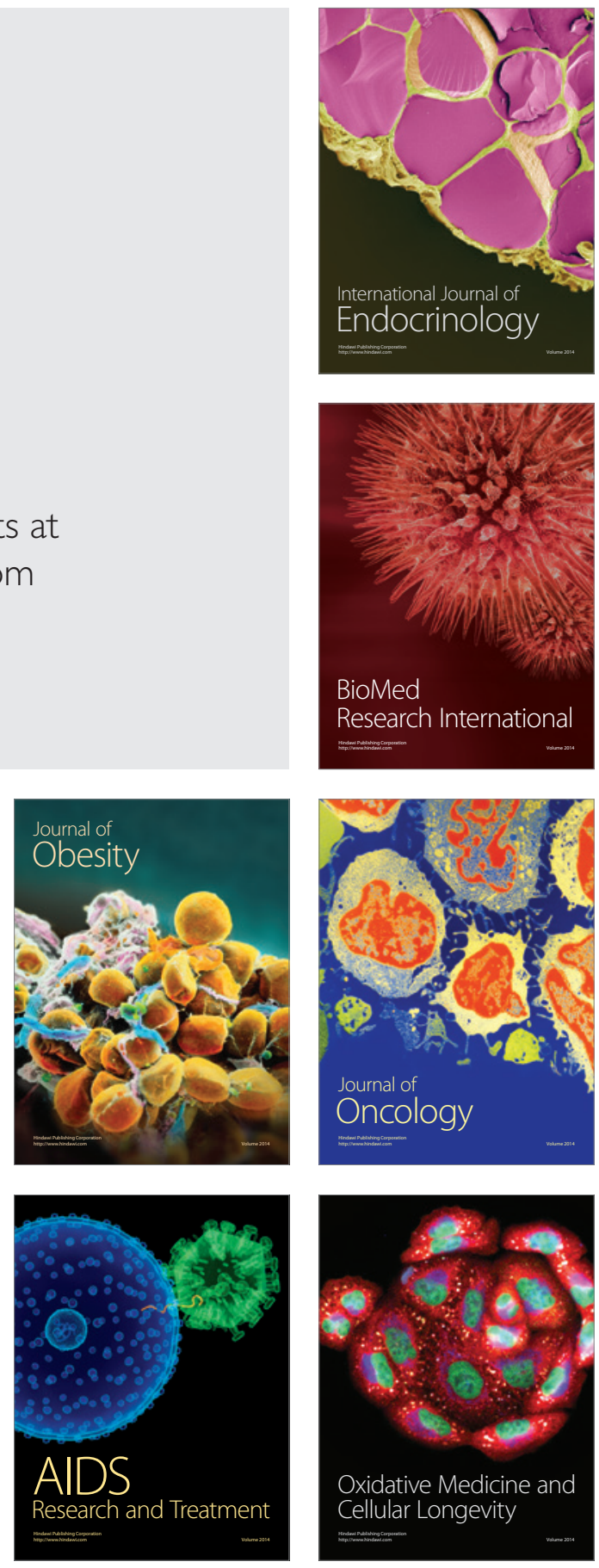